$\overline{\overline{\overline{\text { 要 }}} \overline{\overline{\text { 報 }}}}$

農業気象 (J. Agr. Met.) 45 (4): 277-280, 1990

\title{
Measurement of the Sap Flow Rate in Stem of Rice Plant
}

\author{
Tetsuo Sakuratani \\ $\left(\begin{array}{c}\text { Kyushu Natl. Agric. Exp. Stn., } \\ \text { Suya, Nishigoshi 861-11, Japan }\end{array}\right)$
}

In order to apply, to rice plant, a stem heat balance method for measuring the mass flow rate of sap in the stem of plants, we improved our original gauge in the sensitivity. In the reformed gauge, we used a heater of $8 \mathrm{~mm}$ in width which was shorter by $2 \mathrm{~mm}$ than that of the original one and a miniaturized heat flow sensor in which the thermal resistance was provided by an element consisting of a double side tape and an aluminum foil.

The accuracy and the reliability of the reformed gauge were tested by comparing sap flow rate of a potted rice plant measured by the gauge and transpiration rate by the weighing method. The results indicated that the heat balance method was able to be applied to the stem of rice plant with accuracy of the order of $\pm 10 \%$ under medium or high flow, using the modified gauge.

Key words: Sap flow, Stem heat balance, Transpiration.

キーワード：茎熱収支, 蒸散, 蒸散流

\section{Introduction}

In previous papers, we described a stem heat balance method for measuring the mass flow rate of sap in the stem of herbaceous plants (Sakuratani, 1981), and a flexible gauge that can be easily set and removed to/from stems was further devised to measure sap flow rate in plant stems (Sakuratani, 1984). This method has been successfully used to measure sap flow rate in the stems of sugarcane (Sakuratani and Abe, 1985), soybean (Sakuratani, 1987), tomato (Ozawa, 1989) and so on, in studies in plant-water relations. Baker and van Bavel (1987) reconfirmed the validity of the stem heat balance method using sunflower and cotton, and improved the original desgin of the gauge. Using a measuring gauge similar to that improved by Baker and van Bavel, Steinberg et al. (1989) showed that this heat balance method can be also applied to measure sap flow rate of small woody plants. van Bavel (1988) reported recently that in a number of comparisons, made by different workers, between measured weight loss and integrated stem flow rate, the stem or trunk diameter varied from $5 \mathrm{~mm}$ to $80 \mathrm{~mm}$, and the flow

Received October 15, 1989 rate from a few g to nearly $15 \mathrm{~kg}$ per hour.

Studies cited above indicate clearly that the stem heat balance method developed originally for herbaceous crop plants by the author can be applied to various kinds of plants with the stem on which the measuring gauge can be set. However, the application of this method to rice plants did not bring about successful results, mainly because of - low sensitivity of the measuring gauge and of low thermal conductivity of rice stems. On the other hand, crop scientist and agricultural hydrologist have desired to apply the heat balance method to rice plants for measuring rice transpiration in relation to its growth and weather condition.

We have reformed our original device (Sakuratani, 1981) to apply the heat balance method to rice plant, referring to Baker and van Bavel's comment (Baker and van Bavel, 1987) about the improvement of the measuring gauge. This paper describes the construction of reformed measuring gauge and the results of its application.

\section{Design of improved gauge}

The structure of a reformed measuring gauge is substantially the same as that have been shown in 
Fig. 2 in a previous paper (Sakuratani, 1981). However it was made much smaller than the original one to ensure the sensitivity. Although the gauge can be miniaturized by shortening the heater, too short heater causes a lack of thermal equilibrium between the heated xylem fluid and the stem surface, resulting in a large error in the determination of sap flow rate (Ham and Heilman, 1988). From a preliminary experiment we found that a gauge with a heater of $5 \mathrm{~mm}$ in width overestimated the water flow rate in the stem of rice plant. Therefore we used a heater of $8 \mathrm{~mm}$ in width which was shorter by $2 \mathrm{~mm}$ than that of the original gauge. In addition, to increase the thermal conductance of the heating element, a $0.1 \mathrm{~mm}$

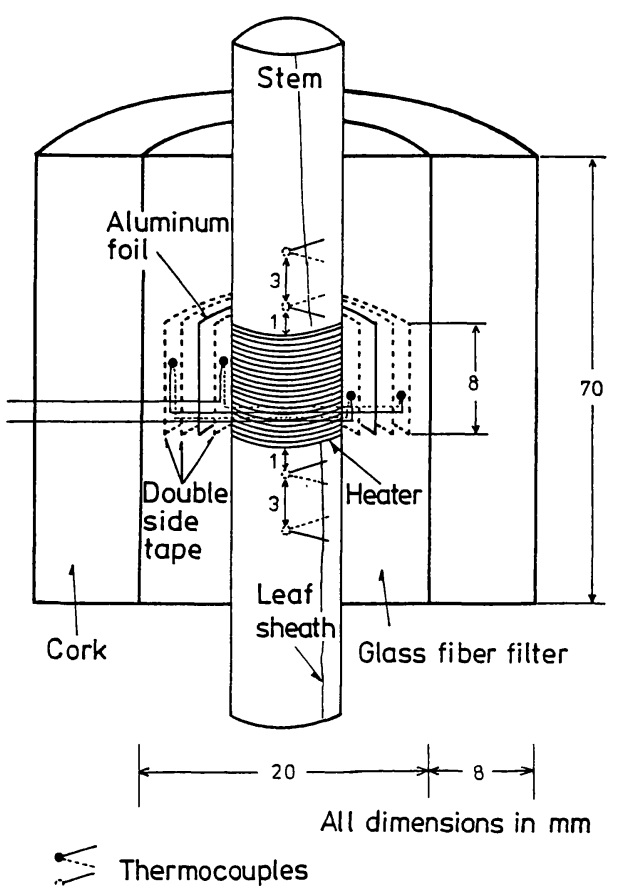

Fig. 1. Structure of the gauge for measuring sap flow rate in the stem of rice plant.

Notes: 1) The distance between the heater and the nearest thermocouples is $1 \mathrm{~mm}$, and that between the thermocouples in each pair located above and below the heater is $3 \mathrm{~mm}$.

2) The thickness of the cork and glass fiber filter is, respectively, $8 \mathrm{~mm}$ and $6-7 \mathrm{~mm}$, and their length is $70 \mathrm{~mm}$. The insulation of the latter is made by wrapping a sheet of glass fiber filter around the gauge. enameld constantan wire was used as the material of the heater, in place of a $0.1 \mathrm{~mm}$ silk-insulated Manganine wire used in our original device.

The heat flow sensor detecting heat loss from the surface of the heater was also minified in scale as possible. It consists of a double side tape, an aluminum foil and four thermocouples of $0.1 \mathrm{~mm}$ diameter enameld copper-constantan wire (Fig. 1). It should be noticed that the thermal resistance between the inside and outside of the sensor is provided by a very thin element consisting of two sheets of a double side tape and a single sheet of an aluminum foil sandwiched between the tapes. The thermocouples for measuring temperature difference between the inside and outside of the element are mounted on its both sides symmetrically.

The thermocouples for detecting stem temperatures at the respective two points above and below the heater were inserted between outer and inner leaf sheaths to measure the stem temperatures accurately as possible.

\section{Test of the gauge}

The accuracy and the reliability of the modified gauge were tested by comparing sap flow rate of a potted rice plant (cultivar Nishihomare) measured by the gauge and transpiration rate by the weighing method. The plant was raised in a pot with the cross-sectional area of $100 \mathrm{~cm}^{2}$. In the young panicle formation stage all tillers were cut and the gauge was mounted on the surface of the main stem at about $10 \mathrm{~cm}$ above the water surface.

The gauge set on the stem was comletely covered by insulation consisting of cork and glass fiber filter (Fig. 1) to minimize more effectively influence of fluctuation in solar radiation and air temperature. The latter was used not only as an insulation but also as an absorber of very small amount of water droplets which may occur by transpiration from the stem surface.

Heat supply to the heater was $0.03 \mathrm{~W}$. The electrical signals from the gauge were recorded through a low-noise amplifier on a multi-channel automatic recoeder of $10 \mathrm{mV}$ in the maximum scale.

The amount of transpiration from a potted rice plant was measured by weighing the pot at an interval of 30 minutes throughout daytime. In 
this case, the water surface of the pot was completely covered by aluminum foil to retard evaporation from the water surface. The sensitivity of the balance was $0.1 \mathrm{~g}$. The measurements were made in outdoor condition during the daylight hours on $10-11$ and 22-23 August 1989. Rice plants with stems of $35 \mathrm{~mm}^{2}$ and $23 \mathrm{~mm}^{2}$ in cross section were used, respectively, in the former and latter experiments.

After each measurment was finished, the plant was enclosed with a black polyethylene bag of which the inside was moistened to determine a gauge factor, namely a conductance of the heat flow sensor under conditions that sap flow rate is assumed to be null.

\section{Results and discussion}

Figure 2 compares the sap flow rate determined by the modified gauge and the transpiration rate measured by the weighing method. The sap flow rate was in good agreement with the transpiration rate except for several points over a range of considerably low transpiration rate. The underestimation of sap flow rate over this range was attributed to the poor response of the heat flow sensor to the flow rates. Since the stem of rice plant has relatively low thermal conductivity (Sakuratani, 1979) owing to developed pneumatic system, the thermal response of the gauge to the heated fluid may be lowered, especially over a

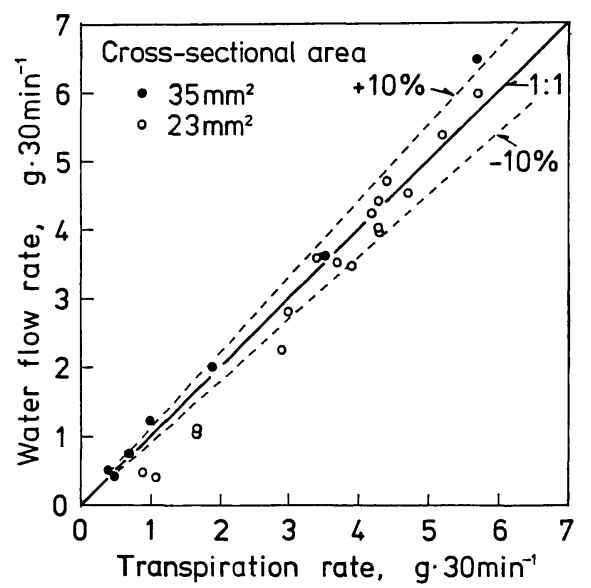

Fig. 2. Comparison of the transpiration rate measured by weighing method and the sap flow rate determined by the improved measuring gauge. lower flow rate, and tend to be influenced by the complicated physical property of the stem, such as the proportion of aerenchyma to cross section. The discrepancy in the estimation over a range of lower flow rate between the two test plants may arise from the difference in such a property.

In conclusion, the heat balance method can be applied to the stem of rice plant, using the modified device, with an accuracy of the order of \pm 10 $\%$ under medium or high flow.

\section{Acknowledgment}

The author would like to acknowledge Professor Z. Uchijima, Ochanomizu University, for helpful comments on the manuscript.

\section{References}

Baker, J. M. and van Bavel, C. H. M., 1987: Measurement of mass flow of water in the stems of herbaceous plants. Plant cell Environ., 10, 777782.

Ham, J. M. and Heilman, J. L., 1988: Evaluation of a heat balance stem flow gauge during high flow. Biophysical Measurements and Instrumentation, A Symposium Honoring Champ B. Tanner.

Ozawa, K., 1989: Effect of foliar mist spraying on root elongation of tomato plants. J. Agr. Met., 45, 19-23*.

Sakuratani, T., 1979: Apparent thermal conductivity of rice stem in relation to transpiration stream. J. Agr. Met., 34, 177-187.

Sakuratani, T., 1981: A heat balance method for measuring water flux in the stem of intact plants. J. Agr. Met., 37, 9-17.

Sakuratani, T., 1984: Improvement of the probe for measuring water flow rate in intact plants with the stem heat balance method. J. Agr. Met., 40, 273-277.

Sakuratani, T., 1987: Studies on evapotranspiration from crops, (2) Separate estimation of transpiration and evaporation from a soybean field without water shortage. J. Agr. Met., 42, 309-317.

Sakuratani, T. and Abe, J., 1985: A heat balance method for measuring water flow rate in stems of intact plants and its application to sugarcane plants. $J A R Q, 19,92-97$.

Steinberg, S., van Bavel, C. H. M. and McFarland, M. J., 1989: A gauge to measure mass flow rate of sap in stems and trunks of woody plants. $J$. Amer. Soc. Hort. Sci., 114, 466-472. 
van Bavel, C. H. M., 1988: Absolute measurement of the sap flow rate in stems of intact plants. Biophysical Measurements and Instrumentation,
A Symposium Honoring Champ B. Tanner. * written in Japanese with English summary

水稲茎部の蒸散流測定への茎熱収支法の適用

桜 谷 哲 夫

(九州農業試験場) 